\title{
Optical Birefringence of Polyisobutylene during Creep and Recovery
}

\author{
P. H. Mott, A. Rizos, ${ }^{\dagger}$ and C. M. Roland* \\ Naval Research Laboratory, Chemistry Division, Code 6120, Washington, DC 20375-5342 \\ Received J anuary 16, 2001
}

\begin{abstract}
Creep and recovery rheooptical measurements were conducted on linear polyisobutylenes, with viscosity-average molecular weights in the range from $4.2 \times 10^{5}$ to $4.7 \times 10^{6} \mathrm{~g} / \mathrm{mol}$. To isol ate the contribution of chain ends to the birefringence, the temperature of each experiment was adjusted to yield equivalent creep strains for each sample. Higher molecular weight PIB exhibited less change in the birefringence during creep, but the birefringence during recovery was independent of molecular weight. The sign of the birefringence during the stress-free recovery was opposite (i.e., corresponding to tension) to that during creep, even though the macroscopic deformation was compression.
\end{abstract}

\section{Introduction}

Optical anisotropy in homogeneous polymers is caused by orientation of the chain units; thus, rheooptical measurements are a useful extension to mechanical experiments. The stress optical rule relates the birefringence, $\Delta \mathrm{n}$, to the true stress, $\sigma$

$$
\Delta \mathrm{n}(\mathrm{t})=\mathrm{C} \sigma(\mathrm{t})
$$

with the stress optical coefficient, $C$, being a material property. Although there are limits to the applicability of eq $1,{ }^{1-3}$ it is used to deduce stresses, ${ }^{4}$ including the normal stress, 5,6 in both linear and nonlinear steadystate flow.

Application of eq 1 to transient viscoelastic experiments is problematic. For example, during stress relaxation of polyisobutylene melts, Bergl und and Taylor ${ }^{7}$ found that $C$ varied with stress. They also measured a residual birefringence during zero-stress recovery, tentatively ascribed to strain-induced crystallinity. Similarly, Saunders ${ }^{8}$ reported a small residual bi refringence in un-cross-linked natural rubber recovering from creep loading, although $\Delta \mathrm{n}$ was proportional to stress during the creep. Deviations from eq 1 have al so been observed during transient shear flow of polyethylene ${ }^{9}$ and stress relaxation of 1,2-polybutadiene ${ }^{10}$ and creep of poly(vinyl chloride) ${ }^{11}$ and 1,4-polybutadiene. ${ }^{12}$ Any change in $\Delta \mathrm{n}$ during a creep/recovery experiment reflects departure from the stress optical rule.

The extensional creep compliance, defined as

$$
\mathrm{D}(\mathrm{t})=\frac{\epsilon(\mathrm{t})}{\sigma}
$$

in which $\epsilon$ is the creep strain, can be expressed as the sum of a recoverable part, $D_{R}(t)$, and the permanent deformation,

$$
\mathrm{D}(\mathrm{t})=\mathrm{D}_{\mathrm{R}}(\mathrm{t})+\frac{\mathrm{t}}{\eta}
$$

where $\eta$ is the viscosity. Qualitatively consistent with very limited experimental data is the prediction ${ }^{13,14}$ that $\Delta \mathrm{n}$ should be proportional to the recoverable strain,

† Permanent address: Department of Chemistry Department and Foundation for Research and Technology, Heraklion 71409, Crete, Greece.

$$
\Delta \mathrm{n}(\mathrm{t})=\mathrm{C} \frac{\epsilon_{\mathrm{R}}(\mathrm{t})}{\mathrm{D}_{\mathrm{R}}(\mathrm{t})}
$$

Only at long times, when steady state is attained and $D_{R}(t)$ becomes constant, does the stress optical rule strictly adhere.

A more striking deviation from eq 1 was seen during recovery experiments on 1,4-polybutadiene melts and networks. ${ }^{12}$ U pon removal of the stress, a slow decay of birefringence occurred, consistent with retarded recovery of the chain segments to an isotropic configuration. However, the sign of the bi refringence during recovery, $\Delta \mathrm{n}_{\mathrm{R}}$, was opposite to that during creep, ${ }^{12}$ implying that chain segments have a net orientation opposite to the macroscopic deformation. This anomaly, also seen in creep of PVC bel ow $\mathrm{T}_{\mathrm{g}}, 11$ is a qual itative departure from theory. One hypothesis ${ }^{14}$ is that dangling chain ends, having relaxed during creep, assume an opposite orientation during recovery. A similar premise was invoked to explain recovery of un-cross-linked rubber after partial stress relaxation. ${ }^{15,16}$ The purpose of the present study is to examine the possibility that a sign change of the bi refringence during creep-recovery reflects the contribution from chain ends. ${ }^{14}$ The present experiments were carried out on polyisobutylene melts, having molecular weights and hence chain end concentrations, which varied by a more than a factor of 10 .

\section{Experimental Section}

Linear polyisobutylenes (PIB) were obtained from SigmaAldrich and Exxon and had the viscosity-average molecular weights, $M_{v}$, listed in Table 1 . Cylindrically shaped test specimens (18.6 $\mathrm{mm}$ high $\times 12.3 \mathrm{~mm}$ diameter) were prepared by compression mol ding for $2 \mathrm{~h}$ at $190^{\circ} \mathrm{C}$. These were verified to have no initial birefringence. To prevent bubble formation in the lowest molecular weight PIB, samples were stored at $-18^{\circ} \mathrm{C}$ prior to measurements.

The rheooptical experiments utilized a modified I Mass Corp. Dynastat (Figure 1). The compressive load (ca. $22 \mathrm{kPa}$ ) reached a constant value in $\approx 0.3 \mathrm{~s}$ and typically was maintained for $1000 \mathrm{~s}$. Adhesion of the samples to the test fixture caused bulging, which increased during the creep. The midpoint diameter is given by ${ }^{17-19}$

$$
d(t)=d_{0}\left(1-\frac{3}{4} \epsilon(t)\right)
$$

where $d_{0}$ is the initial diameter. The increase in $d$ causes a 
Table 1. Molecular Weights, Experimental Temperatures, and Total and Recoverable Creep Compliance for Linear Polyisobutylenes

\begin{tabular}{lcrrc}
\hline polymer & $\mathrm{M}_{\mathrm{v}}(\mathrm{g} / \mathrm{mol})$ & $\mathrm{T}\left({ }^{\circ} \mathrm{C}\right)$ & $\mathrm{D}\left(10^{3} \mathrm{~s}\right)^{\mathrm{a}}$ & $\mathrm{D}_{\mathrm{R}}\left(4 \times 10^{3} \mathrm{~s}\right)^{\mathrm{a}}$ \\
\hline PIB-I & $4.2 \times 10^{5}$ & 30 & $10.8 \pm 0.8$ & $9.0 \pm 0.7$ \\
PIB-m & $9.0 \times 10^{5}$ & 50 & $7.6 \pm 0.3$ & $6.4 \pm 0.4$ \\
PIB-h & $4.7 \times 10^{6}$ & 143 & $7.4 \pm 0.2$ & $6.0 \pm 0.2$
\end{tabular}

a In $\mathrm{MPa}^{-1}$.

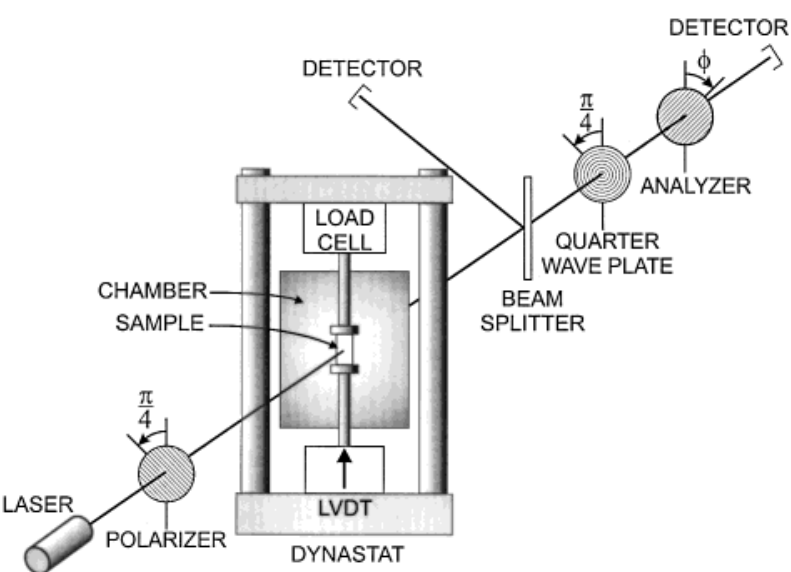

Figure 1. Schematic of the apparatus used to simultaneously measure birefringence, stress, and strain during creep and recovery.

small decrease in $\sigma$, which was accounted for in the analysis. For the most compliant polymer, this stress change was less than $17 \%$. During both creep and recovery, the sample displacement was measured using a linear voltage differential transducer (LVDT). A few creep experiments, without optical measurements, were carried out in shear (torsion) on a Haake Rheostress RS 150.

The birefringence was measured at the midpoint using a modified Sénarmont compensator, ${ }^{20}$ as depicted in Figure 1. Most measurements were carried out with the analyzer orthogonal to the incident light ( $\phi=\pi / 4$ in the figure), with the birefringence the given by

$$
\begin{aligned}
\Delta \mathrm{n}=\frac{\Lambda}{2 \pi \mathrm{d}}\left[\pi\left(\mathrm{i}+\frac{1+(-1)^{\mathrm{i}-1}}{2}\right)+\right. & \\
& \left.(-1)^{\mathrm{i}} \arccos \left(1-\frac{2 \mathrm{l}}{\mathrm{I}_{\mathrm{M}}}\right)+\left(2 \phi-\frac{\pi}{2}\right)\right]
\end{aligned}
$$

where $\mathrm{i}$ is the mode, $\Lambda$ the wavelength $(632.8 \mathrm{~nm})$, I the normalized intensity, and $I_{M}$ the maximum value of I (corresponding to $\pi / 2$ retardation). Although this configuration provides the best sensitivity, the direction of rotation of the plane polarized light is not determined because the cosine is an even function. Thus, the sign of the birefringence was determined in separate experiments, by fixing the analyzer at $\phi=0(\pi / 4$ from the incident light orientation), which breaks the symmetry.

\section{Results}

Displayed in Figure 2 is the shear creep curve for PIB-I at $30^{\circ} \mathrm{C}$. Note that steady state is only approached beyond $20000 \mathrm{~s}$, which is a factor of 20 longer than the creep time used in the rheooptical experiments. Since our objective was to determine the contribution to the optical response from chain ends, the experiments were carried out to the same level of creep strain for each of the three PIB. Accordingly, we empirically determined the temperature at which each sample would exhibit the same creep compliance. These temperatures and the obtained J (1000 s) are listed in Table 1. For the same

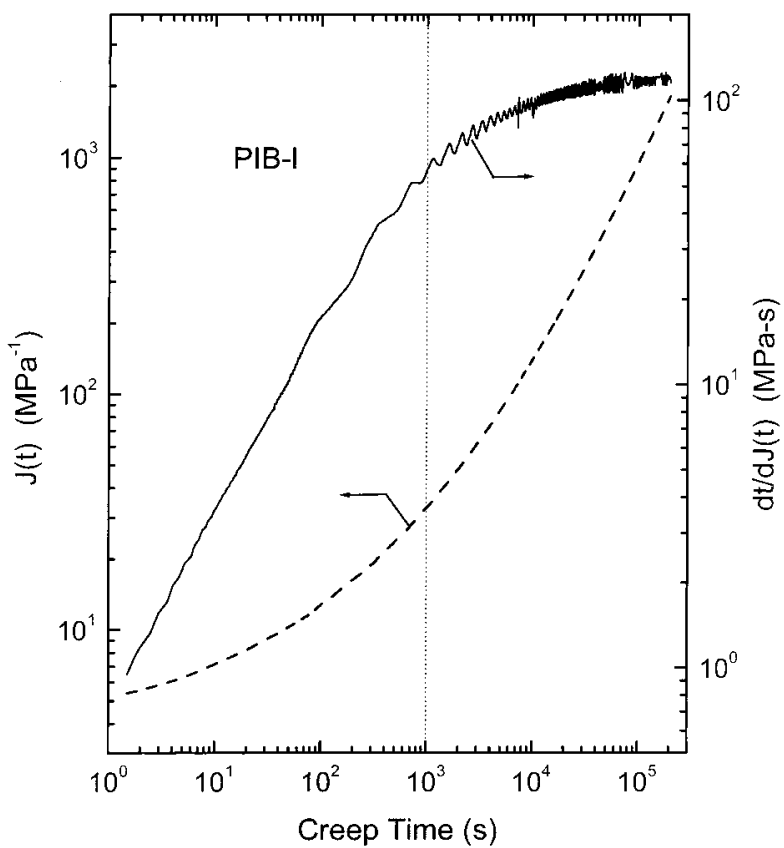

Figure 2. Shear creep compliance and apparent viscosity, measured at $30^{\circ} \mathrm{C}$ with $\sigma=0.5 \mathrm{kPa}$, for polyisobutylene with a molecular weight of $420000 \mathrm{~g} / \mathrm{mol}$. The rheooptical measure ments were terminated at $1000 \mathrm{~s}$, as indicated by the vertical line, which is prior to attainment of steady-state flow.

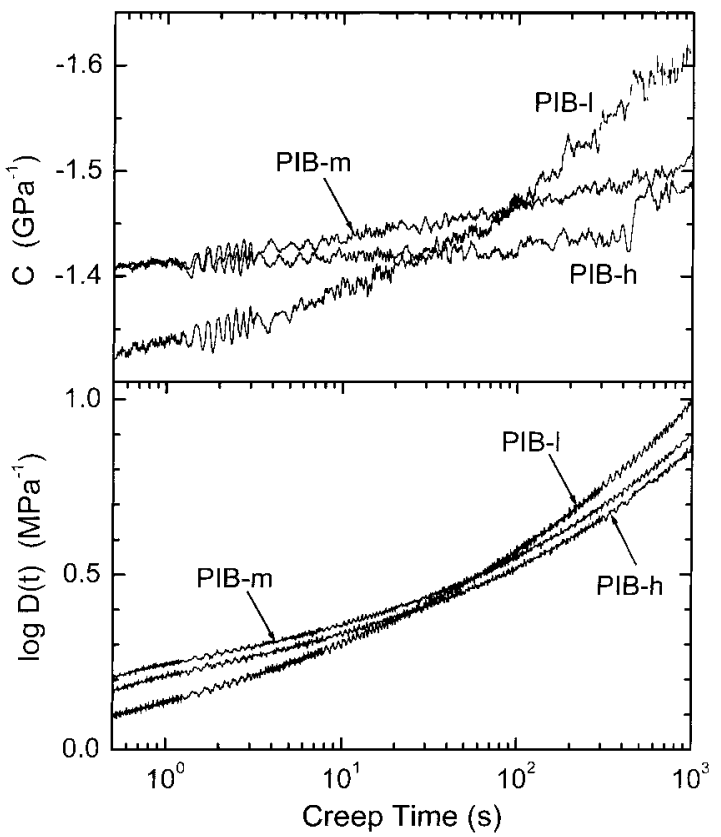

Figure 3. Stress-optical coefficient, C, and the creep compliance, $D$, as a function of creep time for the polyisobutylenes under compressive load. Displayed data are the average of a couple of measurements. The respective temperatures are those listed in Table 1.

stress and time of creep, comparable strains were achieved. An order of magnitude increase in the molecular weight is compensated by about a 115 deg temperature increase.

Representative creep and birefringence data, for each PIB at its respective measurement temperature, are shown in Figure 3. The magnitude of the creep compliance, obtained in compression, agrees with the shear data for PIB-I in Figure 2 (i.e., $D(t)=J(t) / 3$ ). The value of the stress optical coefficient, $\mathrm{C}=1.45 \mathrm{GPa}^{-1}$, compares well with previous measurements. ${ }^{21-23}$ An inter- 


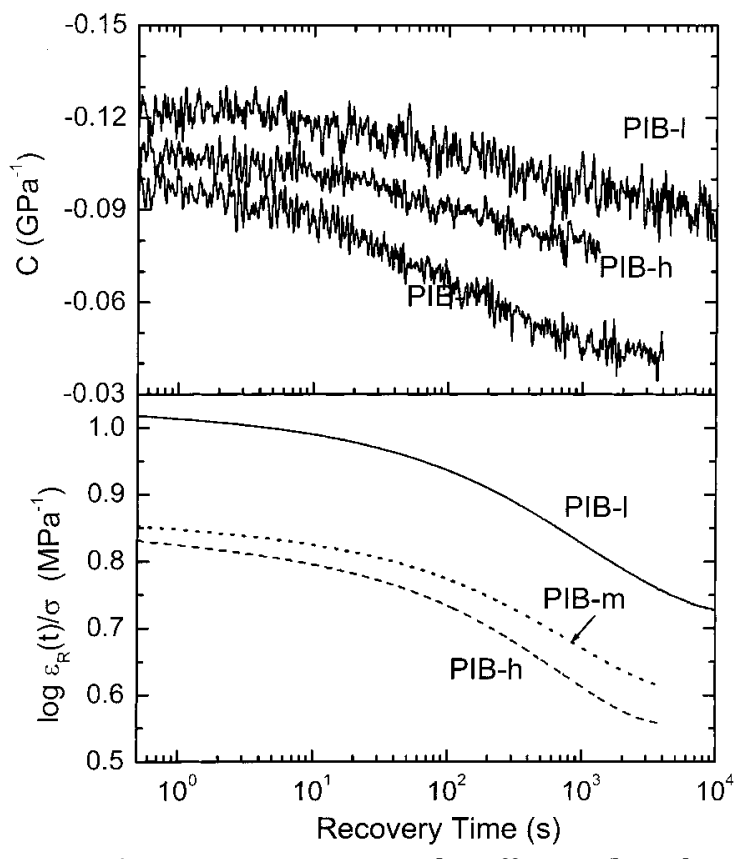

Figure 4. Apparent stress-optical coefficient (based on the creep stress) and the recoil strain (normalized by the creep stress), during recovery for the polyisobutylenes. The respective temperatures are those listed in Table 1.

esting feature is the small, but consistent, increase in $\mathrm{C}$ during creep. Seen previously seen in both linear and cross-linked 1,4-polybutadiene, ${ }^{12}$ the magnitude of this increment decreases with increasing mol ecular weight. Since steady-state was not attained (viz. Figure 2), $\Delta \mathrm{n}$ does not level off during the $1000 \mathrm{~s}$ creep period.

Figure 4 displays the corresponding creep-recovery data, expressed as the recoil strain divided by the stress during the prior creep. Measurable birefringence can be observed during the stress-free recovery, with a magnitude about $5 \%$ of the $\Delta n$ prior to removal of the stress. Any systematic differences in recovery birefringence for the three polymers was beyond the reproducibility of the experiment; that is, a 10-fold increase in chain ends yiel ded no discernible increase in birefringence. The recovery was terminated after $4000 \mathrm{~s}$, although full recovery required about a decade longer. Ultimately the samples became free of birefringence, with an unrecovered strain (permanent set) of about $9 \%$, almost half of the strain after $1000 \mathrm{~s}$ of creep.

Of interest is the sign of the recovery birefringence. This was obtained by fixing the analyzer angle, $\phi$, to zero (Figure 1 ). As seen in the representative results for PIB-m in Figure 5, upon application of the stress, the intensity decreases from an initial value of $I_{M} / 2$, thereafter varying sinusoidally (eq 6). The sign of this birefringence is established by the initial decrease of intensity (value falls bel ow $I_{M} / 2$ ). Unl oading the sample reverses this oscillation, with the intensity during recovery slowly returning to $\mathrm{I}_{\mathrm{M}} / 2$. Note that the intensity approaches its initial value from above, i.e., opposite to the initial response. Thus, after removal of the stress, the sign of $\Delta \mathrm{n}$ is opposite (corresponding to extension) to that during creep, even though the macroscopic deformation remains compression throughout the experiment.

\section{Discussion}

The anomalous change in the sign of $\Delta \mathrm{n}$ upon stress removal is intriguing, since it reveals a net segment

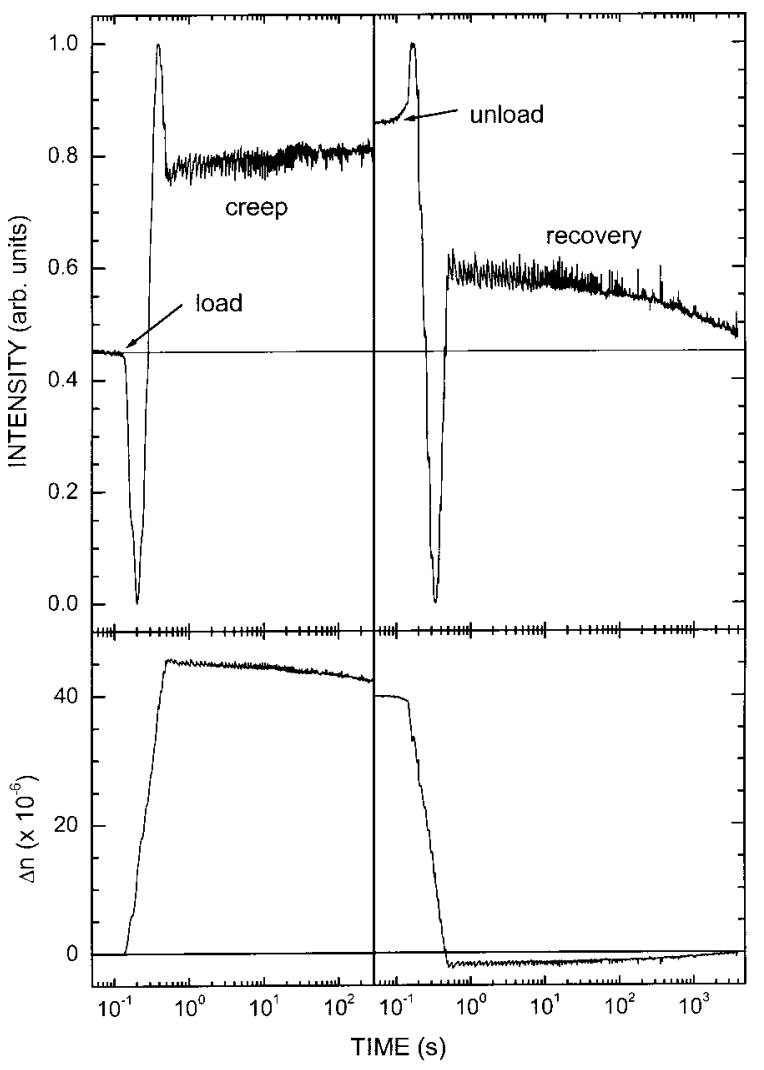

Figure 5. Representative data obtained on PIB-m with the analyzer angle, $\phi$, fixed at zero, to determine the sign of the birefringence (see text for details). The data below ca. $1 \mathrm{~s}$ reflect the instrumental rise time. The decrease in $\Delta n$ during creep is caused by the reduction in stress due to the changing cross-sectional area; correction for this yields the increase in stress-optical coefficient seen in Figure 3.

orientation during recovery opposed not only to the segment orientation during creep but also to the macroscopic deformation. One possi ble explanation ${ }^{14}$ is that chain ends rapidly respond to removal of the compressive load, adopting a transient extended configuration. The contribution of these chain ends to the measured birefringence conceivably could cause a reversal in the sign of $\Delta \mathrm{n}$. However, increasing the molecular weight by a factor of 11 increase did not diminish the magnitude of the recovery birefringence, and PIB of halfmillion molecular weight still exhibits the effect. We conclude that the sign reversal is not likely due to chain ends, and the origin of the anomaly remains an open question.

It has been suggested ${ }^{16}$ that when the stress is removed prior to the attainment of mechanical equilibrium, the recovery is governed by a competition between unrelaxed network chains and those having equilibrated to the imposed compression. This idea has been used to describe semiquantitatively the recoil following partial stress relaxation of uncrosslinked rubbery polymers. ${ }^{15}$ It is also similar to an analysis of the residual (zerostress) birefringence of double-network rubbers. ${ }^{3}$ An explanation for the birefringence of double networks is predicated on the idea that the strain dependence of the stress optical coefficient is different for extension and compression, as known from rubber elasticity theory 24 as well as experimentally. ${ }^{25,26}$ As we have discussed previously, 12 the change in sign of $\Delta \mathrm{n}$ upon recovery, as observed herein, may reflect a delicate balance within the distribution of chain orientations during creep flow, 
prior to attainment of steady state. More generally, reversing deformations are known to exhibit anomalies, including unexpectedly small stresses. ${ }^{27-30}$ This aspect of the transient rheooptical behavior of polymers remains to be understood.

Acknowledgment. This work was supported by the office of Naval Research.

\section{References and Notes}

(1) Read, B. E. Polym. Eng. Sci. 1983, 23, 835.

(2) Mott, P. H.; Roland, C. M. Macromolecules 1998, 31, 7095

(3) Mott, P. H.: Roland, C. M. Macromolecules 2000, 33, 4132

(4) J aneschitz-Kriegl, H. Polymer Melt Rheology and Flow Birefringence; Springer-Verlag: Berlin, 1983.

(5) Pearson, D. S.; Kiss, A. D.; Fetters, L. J .; Doi, M. J . Rheol. 1989, 33, 517.

(6) Rochefort, W. E.; Heffner, G. W.; Pearson, D. S.; Miller, R. D.: Cotts, P. M. Marcomolecules 1991, 24, 4861.

(7) Berglund, C. A.; Taylor, C. R. J . Polym. Sci., Polym. Phys. d. 1976, 14, 2129.

(8) Saunders, D. W. Trans. Faraday Soc. 1956, 52, 1414.

(9) Dexter, F. D.; Miller, J. C.; Philippoff, W. Trans. Soc. Rheol. $1961,5,193$.

(10) Noordermeer, J. W. M.; Ferry, J . D. J . Polym. Sci., Polym. Phys. Ed. 1976, 14, 509.

(11) Andrews, R. D.; Kazama, Y.J . Appl. Phys. 1968, 39, 4891

(12) Mott, P. H.; Roland, C. M. Macromolecules 1996, $29,8492$.

(13) Philippoff, W. Trans Soc. Rheol. 1961, 5, 163.
(14) Berry, G. C. Polymer Rheology: Principles, Techniques and Applications, to be published.

(15) Djiauw, L. K.; Gent, A. N. J . Polym. Sci. 1974, C48, 159.

(16) Taylor, C. R.; Ferry, J . D. J . Rheol. 1979, 23, 533.

(17) Gent, A. N.; Lindley, P. B. Proc. Inst. Mech. Eng, London 1959, 173, 111.

(18) Gent, A. N.; Henry, R. L.; Roxbury, M. L. J . Appl. Mech. 1974 $41,855$.

(19) Mott, P. H.; Roland, C. M. Rubber Chem. Technol. 1995, 68, 739.

(20) Bennett, J . M. Polarizers. In Handbook of Optics, 2nd ed.; Bass, M., et al., Eds.; McGraw-Hill: New York, 1995; Vol. II.

(21) Stein, R. S.; Holmes, F. H.; Tobolsky, A. V. J . Polym. Sci. 1954, 14, 443

(22) Berglund, C. A.; Taylor, C. A. J . Polym. Sci., Polym. Phys. Ed. 1976, 14, 2129

(23) Okamoto, H.; I noue, T.; Osaki, K. J . Polym. Sci., Polym. Phys. Ed. 1995, 33, 1409.

(24) Kloczkowski, A.; Mark, J . E.; Ermin, B. Comput. Polym. Sci. 1995, 5, 37

(25) Erman, B.; Flory, P. J . Macormolecules 1983, 16, 1607.

(26) Erman, B.; Flory, P. J. Macormolecules 1983, 16, 1601.

(27) Ferry, J . D. Viscoelastic Properties of Polymers; Wiley: New York, 1980.

(28) Larson, R. G. Constitutive Equations for Polymer Melts and Solutions; Butterworths: Boston, 1988

(29) Roland, C. M. J . Rheol. 1989, 33, 659.

(30) Santangelo, P. G.; Roland, C. M. Rubber Chem. Technol. 1992 65, 965.

MA010068E 